\title{
Reliability Analysis of Poll Data with Novel Entropy Information Measure in Multicriteria Decision-Making Based upon Picture Fuzzy Environment
}

\author{
Ravinder Kumar, ${ }_{1}^{1}$ Gaurav Gupta $\left(\mathbb{D},{ }^{1}\right.$ Muhammad Gulzar $\left(\mathbb{D},{ }^{2}\right.$ Dragan Pamucar $\left(\mathbb{D},{ }^{3}\right.$ \\ Neeraj Gandotra, ${ }^{1}$ and Md. Ashraful Alam $\mathbb{1}^{4}$ \\ ${ }^{1}$ Yogananda School of Artificial Intelligence Computers and Data Science, Shoolini University, Solan 173229, HP, India \\ ${ }^{2}$ Department of Mathematics, Government College University Faisalabad, Faisalabad 38000, Pakistan \\ ${ }^{3}$ Department of Logistics, Military Academy, University of Defence in Belgrade, Belgrade 11000, Serbia \\ ${ }^{4}$ Department of Mathematics, Jahangirnagar University, Savar, Dhaka, Bangladesh
}

Correspondence should be addressed to Md. Ashraful Alam; ashraf_math20@juniv.edu

Received 25 August 2021; Revised 9 November 2021; Accepted 3 December 2021; Published 27 February 2022

Academic Editor: Lazim Abdullah

Copyright (c) 2022 Ravinder Kumar et al. This is an open access article distributed under the Creative Commons Attribution License, which permits unrestricted use, distribution, and reproduction in any medium, provided the original work is properly cited.

\begin{abstract}
The polling system has a considerable role in the democratic nation. The uncertainty of the people's participation in polling generally affects the electoral-based system. Therefore, PFS (picture fuzzy set) is the furthermost efficient and useful extension of IFS (intuitionistic fuzzy set) in a fuzzy system capable of precisely handling human perception in the decision-making system. The PFS structure involves the different degrees, i.e., membership, nonmembership, neutral, and hesitancy which are comprehensively applied to such types of complex practical problems in the real-life scenario. This advantage of PFS motivates the author to propose PFSs centred novel entropy measure via this communication, which is comparatively more generalized, reliable, and simplified in place of the existing uncertain measures. The practicability of the proposed present research work is to deal with realworld problems pertaining to the relative importance of the attributes. Therefore, certainly, the proposed novel entropy developed a different approach to handle the uncertainty more precisely as a part of the existing approaches. The validation proof of the proposed entropy measure is proved in an organized manner and practically employed in the perspective of the polling data outcomes about the people's opinions with the VIKOR-TOPSIS approach.
\end{abstract}

\section{Introduction}

In the modern era, fuzzy sets and their various generalized extensions are predominantly utilized by researchers and decision-makers in the multiple domains of the research field. For the useful life, the different researchers broadly used the concept of fuzzy logic in several applications of modern technology, for instance, washing machine [1], modern cars [2], and traffic signals control system [3]. The author in [4] was the pioneer to present the abstract of fuzzy theory.

Later, various authors presented the modified structure of $F_{s s}$ and their efficient use to explore the vagueness and uncertainty in many problems of multicriteria decisionmaking support systems. Initially, the fuzzy set may be possible to prevail only the knowledge about the membership degree $(\mu)$ of the element. It restricts the fuzzy set to the specific domain of $M_{\mathrm{CDM}}$. Further, the author was inspired [5] with the concept of nonmembership function $(v)$ and reshaped the existing structure of $F_{s s}$ and added on one more parameter $\pi: 0 \leq \mu+\nu+\pi \leq 1$ and $I_{F S}$ comes to light. $I_{F s}$ attracts the great attentions of various researchers, authors, and decision-makers across the globe because of its feature of presenting $\pi$. It makes $I_{F s}$ more reliable and concise towards the challenges in real-life scenario. In this perception, several authors around the globe contributed to 
the research as per their point of view; for instance, the authors in [6] introduced the idea of homomorphism between the subgroup (cyclic) and $I_{F s}$ subgroup. Further, the authors in [7] developed complex $I_{F s}$ approach which relates with group theory and the authors in [8] proposed some important algebraic structures based upon $(\alpha \beta)$ complex fuzzy - based subgroup. First time, the author was able to validate various parameters of $I_{F s}$ in context of human perception and related various components of $I_{F s}$ as per the public opinion in the voting system, i.e., $\mu$ for Support, $v$ stands for Unsupport, and $\pi$ implies neither support nor unsupport. As $I_{F s}$ handles the $M_{C D M}$ problems more precisely and in efficient manner comparatively $F_{s s}$, however, the researchers analysed that $I_{F s}$ is not applicable comprehensively in all such fuzzy environment-based situations. For instance, in the voting system, the people who are in the mindset of the dilemma are not undertaken in the framework of $I_{F s}$. To encounter such indeterminacy, the authors [9] were motivated with idea of neutral membership degree and incorporated the new component $\eta$ to the present structure of $I_{F s}: 0 \leq \mu+\nu+\eta+\pi \leq 1$ which is known as $P_{F s}$. Therefore, whenever $I_{F s}$ restricts its scope, $P_{F s}$ perfectly handles the uncertainty in a better way. Certainly, the parameter $\eta$ has great importance to capture the logic of the human mind's ambiguity in the behavioural approach towards complex situations. Figure 1 shows the pretty presentation of various parameters from $F_{s s}$ to $P_{F s}$.

The researchers and decision-makers take advantage of this unique feature of $P_{F s}$ and used it tremendously in several applications of modern technologies and social issues. The researcher [10] applied the concept of $P_{F s}$ using the distance measure for the health issues. Nowadays, in various research areas, the researchers are using the framework of $P_{F s}$ in the hybrid form. Further, the authors [11] successively utilized $P_{F s}$-based hybrid distance measure with the concept of rough set theory in selection criteria of the students. In this context, the authors [12] contributed some important correlation coefficients and their application in analysis of clustering and pattern recognition in computing research, and the authors in [13] presented the hybrid form of similarity measures and biparametric distance to handle the uncertainty in medical diagnosis. In the forecasting system, the author [14] significantly implied the $P_{F s}$ feature and proposed the novel method and created the time series model for forecasting. The decision-makers [15] extended the bidirectional projection method for $P_{F s}$ and applied to assess the safety features for construction design.

Recently, the researchers have implied the different picture fuzzy uncertain measures with the use of different methods or approaches to cope up the vagueness in $M_{\mathrm{CDM}}$ challenges. The authors [16] developed the algorithms based upon interaction aggregation operators defined on $P_{F s}$ for complex multivariable decision-making models. Thus, the researcher [17] contributed the concept of cross-entropy in $P_{F s}$ and its application in $M_{\mathrm{CDM}}$ support system. Continuing with the $P_{F s}$ theory, the authors submitted the entropy weighted picture fuzzy information-based clustering-algorithm for segmentation of images. The important entropy similarity measure was proposed by [18], and their application in the decision-making system was developed. Further, the authors [19] worked upon and submitted the divergence information measure of Jenson Tasalli along with its application in decision problems for $P_{F s}$. The concept of $R-S$ norms was broadly used by the authors in $[20,21]$, and the information measure for the picture fuzzy situations was proposed. Moreover, the researchers [22] also proposed the entropy information measure based upon linguistic $P_{F s}$ with $M_{\mathrm{CDM}}$ application. The author [23] proposed the generalized model based upon the concept of maximum entropy negation to explore the information involved in the field of the artificial intelligent decision-making system. Further, the researcher [24] put forwarded the decision-making models to handle the issues like a cost-aware, fault-tolerant, and reliable strategy in complex problems under fuzzy environment. However, the literature findings help us in problem formulation which prevails across the different areas of the research; fuzzy logic and fuzzy sets are considerably applied to capture the ambiguity available in data as well as in practical problems of the real world.

1.1. Research Gap. The human mindsets seem too inefficient to meet the solution of complex multivariable problems in real-time scenarios. Therefore, fuzzy sets are quite proficient and reliable in handling ambiguity and the dilemma approach of human mindsets in complex decision-making issues. $P_{F s}$ can handle the neutral factors involved in the $M_{\mathrm{CDM}}$ problems more efficiently; for instance, in the outcomes of the exit poll in the electoral system, the neutral voters have a vital role. So far, several authors proposed a wide range of diverse information measures and approaches defined on picture fuzzy sets to cope with uncertainty as per their mindsets. However, there is still a scarcity of sophisticated, reliable, and simpler measures defined on $P_{F s}$ to deal with complicated $\mathrm{M}_{\mathrm{CDM}}$ problems in a fuzzy environment. This inspires the authors to work upon the proposed research work. Therefore, the proposed research work certainly overcomes the research gap of the different existing approaches and uncertainty measures of $P_{F s}$.

1.2. Methodology. The different methodologies are proposed to deal with $M_{\mathrm{CDM}}$ problems to select the best alternatives in accordance with the choice of the criteria. The purpose of approaches or techniques is to handle the available data with greater accuracy and to reduce uncertainty. The proposed novel entropy is reliable and more applicable with the complex $M_{\mathrm{CDM}}$ problems allied with the relative importance of the criteria. Therefore, the practicability of novel entropy is applied to the prediction of the polling data; however, the criteria involved in the present problem have the relative importance of the criteria. Therefore, such type of problems handles with the VIKOR approach which provides the compromise solutions. All through the TOPSIS approach was utilized to select the best alternatives irrespective of the relative importance of the different criteria. Therefore, the application part of the proposed entropy was validated with both approaches. 


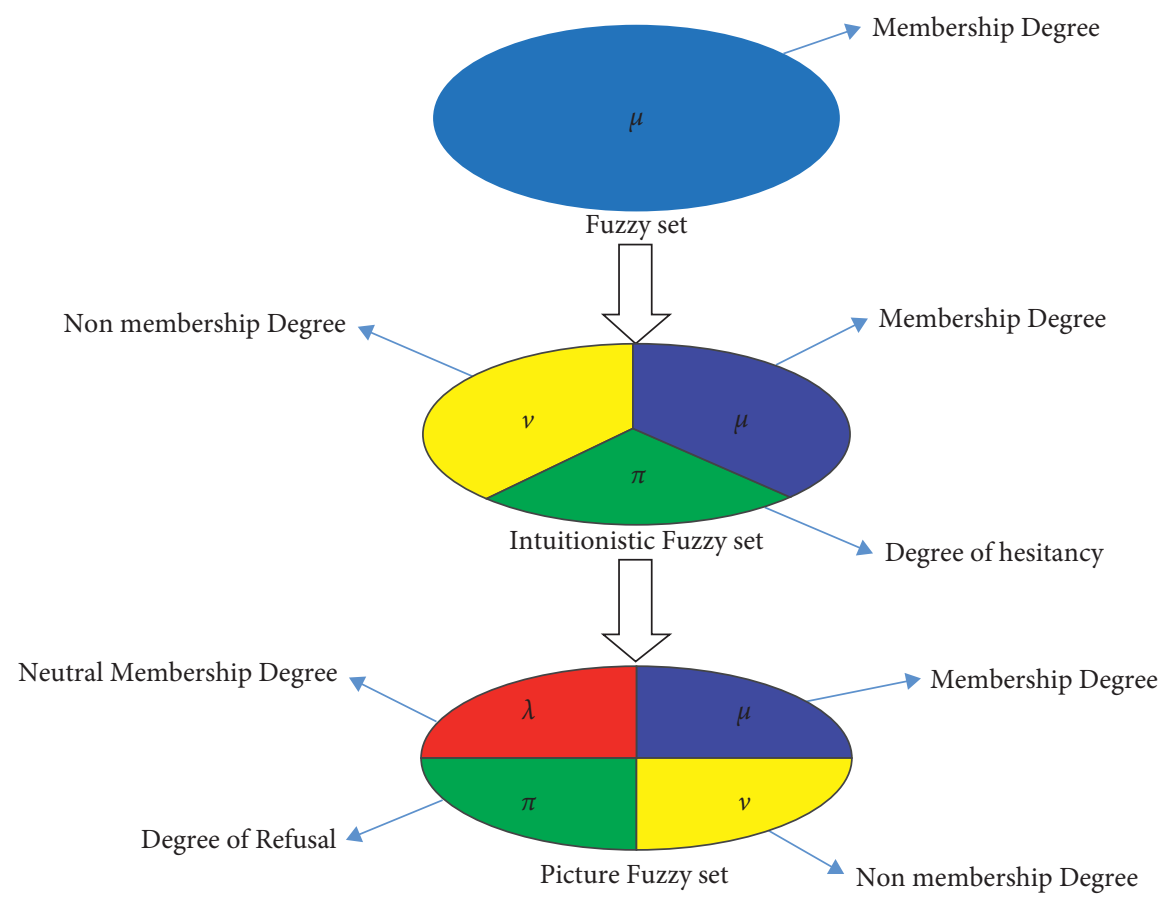

FIgURE 1: The pretty presentation of various parameters from $F_{s s}$ to $P_{F s}$.

Further, the presentation of the proposed work is classified in various parts as shown in Figure 2.

\section{Preliminaries}

Definition 1. . The fuzzy set theory generalized the concept of classical sets, which it perceives as an extension of classical sets. The pioneer of the fuzzy set theory was [4] which defined elements of the fuzzy set $\left(F_{s s}\right)$ in terms of the membership function $\left(\mu_{\nabla}\right)$ on finite universe of discourse, i.e., $Z=\left\{Z_{1}, Z_{2}, Z_{3}, \ldots \ldots Z_{n}\right\}$ and defined $F_{s s}, \nabla$ as

$$
\nabla=\left\{\left\langle Z_{i} \in Z\right\rangle\right\},
$$

where membership function of $F_{s s}$ is $\mu_{\nabla}: Z \longrightarrow[0,1]$ and $\mu_{\nabla}\left(Z_{i}\right)$ signifies the membership degree $\mu_{\nabla}\left(Z_{i}\right)$ of the $Z_{i} \in Z$ in $F_{s s}$. The fuzzy set $\left(F_{s s}\right)$ has only explained $\mu_{\nabla}\left(Z_{i}\right)$ and $1-\mu_{\nabla}\left(Z_{i}\right)$, i.e., nonmembership function and no idea about hesitancy element. The idea of hesitancy element was further introduced by [5] to the existing framework of $F_{s s}$ called the degree of hesitancy.

Definition 2. The fuzzy sets are restricted to employ in certain $M_{\mathrm{CDM}}$ problems, which are unable to handle the uncertainty factor precisely. The idea of $\left(I_{F s}\right)$ intuitionistic fuzzy set was presented by [5] which added on one more important factor, i.e., nonmembership function in the present structure of $F_{s s}$. Consequently, $I_{F s} \Delta$ defined on $Z$ (universe of discourse) is as follows:

$$
\Delta=\left\{\left\langle Z_{i} \in Z\right\rangle\right\},
$$

and satisfies $0 \leq \mu_{\Delta}\left(Z_{i}\right)+v_{\Delta}\left(Z_{i}\right)+\leq 1, \quad \forall Z_{i} \in Z$, along with hesitancy degree $\pi_{\Delta}\left(Z_{i}\right)=1-\mu_{\Delta}\left(Z_{i}\right)-v_{\Delta}\left(Z_{i}\right)$. Apart of this, the functions $\mu_{\Delta}: Z \longrightarrow[0,1]$ and $v_{\Delta}: Z \longrightarrow[0,1]$ stated the membership and nonmembership function of $I_{F s}$, and the terms $\left(\mu_{\Delta}\left(Z_{i}\right)\right)$ and $\left(\nu_{\Delta}\left(Z_{i}\right)\right)$ described the degree of membership and nonmembership of the element belongs to $I_{F s}$. The author in [5] introduced $I_{F s}$ which extend the scope of fuzzy set in decision-making environment. In real-life scenario, the $I_{F s}$ membership, nonmembership, and uncertain degree make the sense of favour, against, and abstain in $\mathrm{M}_{\mathrm{CDM}}$ problems but are unable to describe refusal degree which restricts its scope of application. Therefore, this inconsistency is vanquished in picture fuzzy set $\left(P_{F S}\right)$ to add on one more component "Neutral membership degree" in the present framework of $I_{F s}$ by [9].

Definition 3. Over the period, the decision-makers analysed that $I_{F s s}$ is not feasible towards certain complex issues. The author in [9] presented the concept of a picture fuzzy set, which is an advanced generalized form of fuzzy sets that are more capable of dealing with complex issues in a fuzzy environment. The picture fuzzy set $\left(P_{F S}\right) \nabla$ on $Z$ is defined as

$$
\hat{\nabla}=\left\{\left\langle Z_{i} \in Z\right\rangle\right\} .
$$

with inequality $0 \leq \mu_{\hat{\nabla}}\left(Z_{i}\right)+\eta_{\hat{\nabla}}\left(Z_{i}\right)+\nu_{\hat{\nabla}}\left(Z_{i}\right) \leq 1, \quad \forall Z_{i} \in Z$.

This describes the positive membership degree $\mu_{\hat{\nabla}}\left(Z_{i}\right) \in[0,1]$, neutral membership degree $\eta_{\hat{\nabla}}\left(Z_{i}\right) \in[0$,$] ,$ and negative membership degree $\nu_{\hat{\nabla}}\left(Z_{i}\right) \in[0,1]$. The component $\pi_{\hat{\nabla}}\left(Z_{i}\right)=1-\mu_{\hat{\nabla}}\left(Z_{i}\right)-\eta_{\hat{\nabla}}\left(Z_{i}\right)-v_{\hat{\nabla}}\left(Z_{i}\right)$ is refusal membership degree for each $Z_{i} \in Z$. Therefore, the structure of $P_{F S}$ is more generalized and classified form as compared with $F_{s s}$ and $I_{F s}$ to capture the vagueness in $M_{\mathrm{CDM}}$ practical problems. 


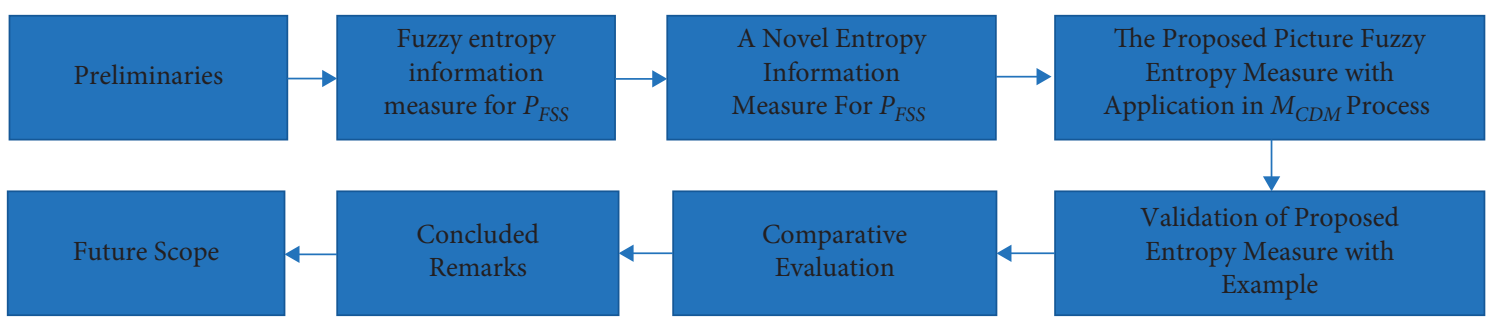

Figure 2: Proposed workflow.

Definition 4. Let $Q$ and $R$ be $P_{F S}$ defined on $Z$.

$$
\begin{aligned}
& Q=\left\{\left\langle Z_{i} \in Z\right\rangle\right\}, \\
& R=\left\{\left\langle Z_{i} \in Z\right\rangle\right\} .
\end{aligned}
$$

The authors in [25] introduced the following important operations and relations for any $Q, R \in P_{F s}(Z)$ defined as follows:

(1) $Q \subseteq R \Leftrightarrow \mu_{Q}\left(Z_{i}\right) \leq \mu_{R}\left(Z_{i}\right), \eta_{Q}\left(Z_{i}\right) \leq$ $\eta_{R}\left(Z_{i}\right), v_{R}\left(Z_{i}\right) \leq v_{Q}\left(Z_{i}\right) \quad \forall Z_{i} \in Z$

(2) $Q=R \Leftrightarrow Q \subseteq R$ and $R \subseteq Q$

(3) $Q^{C}$ (the complement of $\left.Q\right)=\left\{\left\langle Z_{i} \in Z\right\rangle\right\}$
(4) $Q \cap R=\left\{\left\langle\mu_{Q}\left(Z_{i}\right) \wedge \mu_{R}\left(Z_{i}\right), \eta_{Q}\left(Z_{i}\right) \vee \eta_{R}\left(Z_{i}\right)\right.\right.$, $\left.\left.v_{Q}\left(Z_{i}\right) \vee v_{R}\left(Z_{i}\right)\right\rangle \mid Z_{i} \in Z\right\}$

(5) $Q \cup R=\left\{\left\langle\mu_{Q}\left(Z_{i}\right) \vee \mu_{R}\left(Z_{i}\right), \eta_{Q}\left(Z_{i}\right) \wedge \eta_{R}\left(Z_{i}\right)\right.\right.$, $\left.\left.\nu_{Q}\left(Z_{i}\right) \wedge \nu_{R}\left(Z_{i}\right)\right\rangle \mid Z_{i} \in Z\right\}$

Definition 5. Assume that $Q$ and $R$ are two $P_{F s} \in Z$ such that

$$
\begin{aligned}
& Q=\left\{\left\langle Z_{i} \in Z\right\rangle\right\}, \\
& R=\left\{\left\langle Z_{i} \in Z\right\rangle\right\} .
\end{aligned}
$$

There are two distance measures, i.e., Hamming distance measure and Euclidean distance between the two $P_{F s} Q$ and $R$ defined as

$$
\begin{gathered}
H_{D}(Q, R)=0.5 \sum_{i=1}^{n}\left(\left|\mu_{Q}\left(Z_{i}\right)-\mu_{R}\left(Z_{i}\right)\right|+\left|\eta_{Q}\left(Z_{i}\right)-\eta_{R}\left(Z_{i}\right)\right|+\left|\nu_{Q}\left(Z_{i}\right)-\nu_{R}\left(Z_{i}\right)\right|+\left|\pi_{Q}\left(Z_{i}\right)-\pi_{R}\left(Z_{i}\right)\right|\right), \\
E_{D}(Q, R)=\sqrt{\sum_{i=1}^{n}\left\{\left(\mu_{Q}\left(Z_{i}\right)-\mu_{R}\left(Z_{i}\right)\right)^{2}+\left(\eta_{Q}\left(Z_{i}\right)-\eta_{R}\left(Z_{i}\right)\right)^{2}+\left(\nu_{Q}\left(Z_{i}\right)-\nu_{R}\left(Z_{i}\right)\right)^{2}+\left(\pi_{Q}\left(Z_{i}\right)-\pi_{R}\left(Z_{i}\right)\right)^{2}\right\} .}
\end{gathered}
$$

\section{Fuzzy Entropy Information Measure for $P_{\text {FSS }}$}

The entropy information measure is the fuzziness degree of $F_{s s}$. The author [26] introduced the set of postulates based upon probability theory of Shannon for $F_{s s}$

Refinition 6. The entropy is a real function $\theta: F_{s s}(Z) \longrightarrow[0, \infty)$ which satisfies the following axioms:

(1) $P F_{\text {Sharpness }} \hat{\theta}(\hat{Q})=0 \Leftrightarrow \hat{Q}$ defined as the crisp set

(2) $P F_{\text {Maximality }} \cdot \theta(Q)$ acquires maximum value $\Leftrightarrow \mu_{\hat{Q}}=0.5 \forall \quad \hat{Q} \in F_{s S}(Z)$

(3) $P F_{\text {Resolution. }} . \quad \hat{Q}$ and $\hat{R} \in F_{\text {ss }}(Z) \mid \hat{Q} \quad$ is crisper than $\hat{R}$, i.e., $\hat{\theta}(\hat{Q}) \leq \hat{\theta}(\hat{R}) \Rightarrow \mu_{\hat{Q}} \leq \mu_{\hat{R}}$ for $\mu_{\hat{R}} \leq 1 / 2$ and $\mu_{\hat{Q}} \geq$

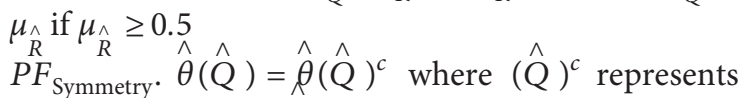
the compliment of $Q$
Definition 7 (see [27]). The entropy is a real function ө: $I_{F s}(Z) \longrightarrow[0, \infty)$ which satisfies the following properties:

(1) $P F_{\text {Sharpness }} . \check{\theta}(\check{Q})=0 \Leftrightarrow \check{Q} \in I_{F s}(Z)$ defined as the crisp set

(2) $P F_{\text {Maximality. }} \check{\theta}(\check{Q})$ is maximum value if $\mu_{\check{Q}}=v_{\check{Q}}=\pi_{\check{Q}}=1 / 3 \quad \forall Q \in I_{F s}(Z)$

(3) $P F_{\text {Resolution. If }} \quad \check{Q}$ and $\check{R} \in I_{F s}(Z) \mid \check{Q}$ is crisper than $\check{R}$, i.e., $\theta(\check{Q}) \leq \check{\theta}(\check{R}) \Rightarrow \mu_{\check{Q}} \leq \mu_{\check{R}}$ and $\nu_{\check{Q}} \leq v_{\check{R}} \quad$ for $\operatorname{maximum}\left(\mu_{\check{R}}, v_{\check{R}}\right)$ $\leq 1 / 3$ and if $\mu_{\check{Q}} \geq \mu_{\check{R}}, v_{\check{Q}} \geq v_{\check{R}}$, then $\min \left(\mu_{\check{R}}, v_{\check{R}}\right) \geq 1 / 3$

(4) $P F_{\text {Symmetry }} . \check{\theta}(\check{Q})=\check{\theta}(\check{Q})^{C}$ where $(\check{Q})^{C}$ denotes the compliment of $\ddot{\theta}$

Moreover, $P_{F S S}$ is the well-known generalized form of $I_{F s}$ with the four components, i.e., $(\mu, \nu, \eta, \pi)$ which hold the condition such that $(\mu, \nu, \eta, \pi) \in[0,1]$ and $\mu+\nu+\eta+\pi=0$. These parameters may be presumed as probability measures 
that characterized the picture fuzzy set. This indicates that entropy measure must have maximum value if all parameters uniformly have the value one-fourth, i.e., $\mu_{Q}=\eta_{Q}=$ $\nu_{Q}=\pi_{Q}=1 / 4$ and must be zero if all the components vanish except one such as

$$
\begin{aligned}
& \mu_{Q}=1, \\
& \eta_{Q}=v_{Q}=\pi_{Q}=0, \\
& \quad \text { or, } \\
& \eta_{Q}=1, \\
& \mu_{Q}=v_{Q}=\pi_{Q}=0, \\
& \quad \text { or, } \\
& v_{Q}=1, \\
& v_{Q}=1, \\
& \mu_{Q}=\eta_{Q}=\pi_{Q}=0, \\
& \text { or, } \\
& \pi_{Q}=1, \\
& \mu_{Q}=\eta_{Q}=v_{Q}=0 .
\end{aligned}
$$

Definition 8. The axiomatic definition of entropy measure for $P_{F S}$ proposed in view of the concept of entropy measure of $I_{F s}$ introduced by [27] is as follows.

The entropy measure is a real function $\theta: P_{F S}(Z) \longrightarrow[0, \infty)$ and agreed with the following axioms:

$P_{F S 1}$ (sharpness). $\theta(Q)=0 \Leftrightarrow P_{F S} Q \in(Z)$ which holds $Q$ is a crisp set

$P_{F S 2}$ (maximality). If $\mu_{Q}=\eta_{Q}=\nu_{Q}=\pi_{Q}=1 / 4 \Rightarrow \theta(Q)$ have the maximum value then

$P_{F S 3}$ (resolution). This property holds if $Q$ is crisper than $\quad R$, i.e., $\theta(Q) \leq \theta(R)$ such that $\mu_{Q} \geq \mu_{R}, \eta_{Q} \geq \eta_{R}, v_{Q} \geq v_{R} \quad$ for $\left(\mu_{R}, \eta_{R}, v_{R}\right) \geq(1 / 4)$, $\mu_{\mathrm{Q}} \leq \mu_{R}, \eta_{\mathrm{Q}} \leq \eta_{R}, \nu_{\mathrm{Q}} \leq \nu_{R}$ for $\left(\mu_{R}, \eta_{R}, \nu_{R}\right) \leq(1 / 4)$
$P_{F S 4}$ (symmetry). If $Q^{c}$ is the complement of $Q$, symmetry implies $\theta(Q)=\theta\left(Q^{c}\right)$

In fact, several authors proposed different uncertain measures on $P_{F s}$ and utilized them to solve the complex multivariable problems. In this context, the novel entropy measure is proposed to enhance the preciseness and improve the reliability and handle the ambiguity of $\mathrm{M}_{\mathrm{CDM}}$ problems in a simpler and more logical way. This would certainly overcome such shortcomings existing in uncertain measures defined on $P_{F s}$. In the next part, a novel entropy information measure has been proposed on $P_{F S S}$, keeping in view these important fundamental concepts.

\section{A Novel Entropy Information Measure for $P_{\text {FSS }}$}

Let us assume the finite set of comprehensive probability distribution signified as $L_{n}=\left\langle\sigma={ }^{\prime \prime} a_{1}, a_{2}\right.$ $\ldots \ldots \ldots a_{n}^{\prime \prime}: a_{i} \geq 0$ and $\left.\quad \sum_{i=1}^{n} a_{i}=1\right\rangle ; n \geq 2$ for any $\delta \in L_{n}$. Firstly, Shannon [28] initiated to define the information measure explained which is widely known as Shannon entropy

$$
R(\delta)=-\sum_{i=1}^{n}\left(a_{i}\right) \log \left(a_{i}\right)
$$

In the passage of time, Zadeh (1965) put forward the concept of fuzzy set which develops the new approach to quantify the uncertainty/fuzziness. Further, in 1968, Zadeh prolonged the concept of Shannon entropy; however, this information was not capable to meet the purpose. The continued efforts of researchers with information measure in 1972 [26] were capable to extend the axioms of Shannon entropy and proposed the new fuzzy information postulates which are accepted widely across the world and set as criteria for fuzzy entropy measure mentioned in Definition 6 This also motivated the authors [26] to propose the fuzzy entropy measure consistent with Shannon entropy presented as

$$
R_{L T}(\nabla)=-\frac{1}{n} \sum_{i=1}^{n}\left[\mu_{\Delta}\left(Z_{i}\right) \log \log \left(\mu_{\Delta}\left(Z_{i}\right)\right)+\left(1-\mu_{\Delta}\left(Z_{i}\right)\right) \log \log \left(1-\mu_{\Delta}\left(Z_{i}\right)\right)\right]
$$

where $\nabla$ and $Z_{i} \in F_{s s}(Z)$.

This developed the author's insight more into $F_{s s}$ and presented different information measures according to their point of view. The authors [29] contributed exponential entropy measure for $I_{F s}$ given as follows: 


$$
\begin{aligned}
R_{R B}(\Delta)= & \frac{1}{n \sqrt{\exp -1}} \\
& \sum_{i=1}^{n}\left(\frac{\mu_{\Delta}\left(Z_{i}\right)+1-v_{\Delta}\left(Z_{i}\right)}{2}\right) \exp \left(\frac{\mu_{\Delta}\left(Z_{i}\right)+1-v_{\Delta}\left(Z_{i}\right)}{2}\right)+\left(\frac{\mu_{\Delta}\left(Z_{i}\right)+1-v_{\Delta}\left(Z_{i}\right)}{2}\right) \exp \left(\frac{\mu_{\Delta}\left(Z_{i}\right)+1-v_{\Delta}\left(Z_{i}\right)}{2}\right)-1,
\end{aligned}
$$

where $\Delta$ and $Z_{i} \in I_{F s}$.

Further, the researchers [30] have explored the idea of entropy measure based on exponential function to $P_{P F S}$ (Pythagorean fuzzy set) given by

$$
R_{R G}(\hat{\Delta})=\frac{1}{n\left(1-(\sqrt[3]{\exp })^{2}\right)} \sum_{i=1}^{n} 1-\exp \left|\mu_{\Delta}^{2}\left(Z_{i}\right)+v_{\hat{\Delta}}^{2}\left(Z_{i}\right)-\pi_{\hat{\Delta}}^{2}\left(Z_{i}\right)\right| \text { where } \hat{\Delta} \text { and } Z_{i} \in P_{\mathrm{PFS}}
$$

Over the period, several authors have introduced the different work on entropy information measure. The authors [31] contributed residual entropy information measure in the application of the group decision-making. The geometric aggregation operators were introduced [32] based upon $I_{F s}$, respectively, with undefined criteria weights and their application in $\mathrm{M}_{\mathrm{CDM}}$. Further, the researcher [33] presented information entropy measure with the generalized form of $I_{F s}$ and utilized in decision-making problems.
With this information as background, in the next part, new entropy measure is proposed to the picture fuzzy set $\left(P_{F S}\right)$ as the generalized form of $I_{F s}$.

Definition 9. The real function $\theta$ is defined on $Q \in P_{F S}(Z)$. The new probability type picture information measure is proposed as follows:

$$
\theta(Q)=\frac{1.582}{n \exp } \sum_{i=1}^{n} \exp -\exp \left|\mu_{Q}\left(Z_{i}\right)+\eta_{Q}\left(Z_{i}\right)-v_{Q}\left(Z_{i}\right)-\pi_{Q}\left(Z_{i}\right)\right|: Q \text { and } Z_{i} \in P_{F S}(Z)
$$

where $\mu_{Q}\left(Z_{i}\right) \longrightarrow$ positive membership degree,

$$
\begin{aligned}
& \eta_{Q}\left(Z_{i}\right) \longrightarrow \text { neutral membership degree, } \\
& v_{Q}\left(Z_{i}\right) \longrightarrow \text { negative membership degree, } \\
& \pi_{Q}\left(Z_{i}\right) \longrightarrow \text { degree of the refusal membership } \\
& 1.582=\frac{\operatorname{Exp}}{\operatorname{Exp}-1} .
\end{aligned}
$$

The validity of information measure is proved if it satisfied the fundamental postulates of entropy measure listed in Definition 8.
4.1. Validation of Proposed Information Measure. Firstly, the following inequalities for any $Q$ and $R \in P_{F S}(Z)$ : $Q$ crisper than $R$ listed in axioms $P_{F S 3}$ are proved:

$$
\left|\mu_{Q}\left(Z_{i}\right)-\frac{1}{4}\right|+\left|\eta_{Q}\left(Z_{i}\right)-\frac{1}{4}\right|+\left|\nu_{Q}\left(Z_{i}\right)-\frac{1}{4}\right|+\left|\pi_{Q}\left(Z_{i}\right)-\frac{1}{4}\right| \geq\left|\mu_{R}\left(Z_{i}\right)-\frac{1}{4}\right|+\left|\eta_{R}\left(Z_{i}\right)-\frac{1}{4}\right|+\left|\nu_{R}\left(Z_{i}\right)-\frac{1}{4}\right|+\left|\pi_{R}\left(Z_{i}\right)-\frac{1}{4}\right|,
$$


and

$$
\begin{aligned}
& \left(\mu_{\mathrm{Q}}\left(Z_{i}\right)-\frac{1}{4}\right)^{2}+\left(\eta_{\mathrm{Q}}\left(Z_{i}\right)-\frac{1}{4}\right)^{2}+\left(v_{\mathrm{Q}}\left(Z_{i}\right)-\frac{1}{4}\right)^{2}+\left(\pi_{\mathrm{Q}}\left(Z_{i}\right)-\frac{1}{4}\right)^{2} \geq\left(\mu_{R}\left(Z_{i}\right)-\frac{1}{4}\right)^{2}+\left(\eta_{R}\left(Z_{i}\right)-\frac{1}{4}\right)^{2} \\
& +\left(\nu_{R}\left(Z_{i}\right)-\frac{1}{4}\right)^{2}+\left(\pi_{R}\left(Z_{i}\right)-\frac{1}{4}\right)^{2} .
\end{aligned}
$$

Proof. If $\quad \mu_{Q}\left(Z_{i}\right) \leq \mu_{R}\left(Z_{i}\right), \eta_{Q}\left(Z_{i}\right) \leq \eta_{R}\left(Z_{i}\right), \quad v_{Q}\left(Z_{i}\right) \leq$ $v_{R}\left(Z_{i}\right)$ and $\pi_{Q}\left(Z_{i}\right) \geq \pi_{R}\left(Z_{i}\right) \quad$ with $\max \left\langle\mu_{R}\left(Z_{i}\right), \eta_{R}\left(Z_{i}\right)\right.$, $\left.\nu_{R}\left(Z_{i}\right)\right\rangle \leq 1 / \quad 4 \Rightarrow \mu_{Q}\left(Z_{i}\right) \leq \mu_{R}\left(Z_{i}\right) \leq 1 / 4$ and $\eta_{Q}\left(Z_{i}\right) \leq \eta_{R}$ $\left(Z_{i}\right) \leq 1 / 4$,

$\nu_{Q}\left(Z_{i}\right) \leq \nu_{R}\left(Z_{i}\right) \leq 1 / 4$ and $\pi_{Q}\left(Z_{i}\right) \geq \pi_{R}\left(Z_{i}\right) \geq 1 / 4$ This proves that equations (14) and (15) are correct.

If if $\mu_{Q}\left(Z_{i}\right) \geq \mu_{R}\left(Z_{i}\right), \eta_{Q}\left(Z_{i}\right) \geq \eta_{R}\left(Z_{i}\right), v_{Q}\left(Z_{i}\right) \geq$ $\nu_{R}\left(Z_{i}\right)$ and $\pi_{Q}\left(Z_{i}\right) \leq \pi_{R}\left(Z_{i}\right) \quad$ with $\min \left\langle\mu_{R}\left(Z_{i}\right), \eta_{R}\left(Z_{i}\right)\right.$, $\left.\nu_{R}\left(Z_{i}\right)\right\rangle \geq 1 / 4 \Rightarrow \mu_{Q}\left(Z_{i}\right) \geq \mu_{R}\left(Z_{i}\right) \geq 1 / 4$ and $\eta_{Q}\left(Z_{i}\right) \geq$ $\eta_{R}\left(Z_{i}\right) \geq 1 / \quad 4, v_{Q}\left(Z_{i}\right) \geq v_{R}\left(Z_{i}\right) \geq 1 / 4$ and $\pi_{Q}\left(Z_{i}\right) \leq \pi_{R}\left(Z_{i}\right)$ $\leq 1 / 4$ which hold (16) and (20).

There are two distance measures, i.e., Hamming and Euclidean distance which are widely used to determine the distance between the two different $I_{F s s}$. The authors in [34] introduced the concept of distance between the two different
$I_{\mathrm{Fss}}$ specifically in terms of their parameters $(\mu, \nu, \pi)$. Subsequently, $P_{\mathrm{FSS}}$ is the generalized form of $I_{F s s}$ which have four components, i.e., $(\mu, \nu, \eta, \pi)$. Therefore, this concept of distance measure is significantly used from $I_{\mathrm{Fss}}$ to $P_{\mathrm{FSS}}$. Thus, inequalities (14) and (15) concluded that $P_{F S} R$ is nearest to the maximum value $\left(\begin{array}{lllll}1 / 4 & 1 / 4 & 1 / 4 & 1 / 4\end{array}\right)$ than $Q$.

Theorem 1. To validate the proof of the novel entropy information measure for $P_{F S}$.

Proof. The proof of the validity of the proposed measure will be established if it agreed with the axioms listed in Definition 8.

$P_{F S 1}$ (sharpness). Initially, we assume $\theta(Q)=0$.

$$
\theta(Q)=\frac{1}{n} \sum_{i=1}^{n} \frac{1.582}{\exp }\left(\exp -\exp \left|\mu_{Q}\left(Z_{i}\right)+\eta_{Q}\left(Z_{i}\right)-v_{Q}\left(Z_{i}\right)-\pi_{Q}\left(Z_{i}\right)\right|\right): Q \text { and } Z_{i} \in P_{F S}(Z)
$$

This will hold if following cases are possible:

$$
\text { If } \begin{aligned}
\mu_{Q}\left(Z_{i}\right) & =1, \\
\eta_{Q}\left(Z_{i}\right) & =v_{Q}\left(Z_{i}\right)=\pi_{Q}\left(Z_{i}\right)=0,
\end{aligned}
$$

or,$$
\eta_{\mathrm{Q}}=1 \mu_{\mathrm{Q}}\left(Z_{i}\right)=v_{\mathrm{Q}}\left(Z_{i}\right)=\pi_{\mathrm{Q}}\left(Z_{i}\right)=0,
$$

or,

$$
\begin{aligned}
v_{Q}\left(Z_{i}\right) & =1, \\
\mu_{Q}\left(Z_{i}\right) & =\eta_{Q}\left(Z_{i}\right)=\pi_{Q}\left(Z_{i}\right)=0,
\end{aligned}
$$

or,

$$
\begin{aligned}
\pi_{\mathrm{Q}}\left(Z_{i}\right) & =1, \\
\mu_{\mathrm{Q}}\left(Z_{i}\right) & =\eta_{\mathrm{Q}}\left(Z_{i}\right)=v_{\mathrm{Q}}\left(Z_{i}\right)=0 .
\end{aligned}
$$

Hence, all the above cases show that $\theta(Q)=0$. This implies that $\theta$ is the crisp set. Therefore conversely, assume that $\theta$ is the crisp set. This provides

$$
\text { either } \begin{aligned}
\mu_{Q}\left(Z_{i}\right) & =1 \\
\eta_{Q}\left(Z_{i}\right) & =v_{Q}\left(Z_{i}\right) \\
& =\pi_{Q}\left(Z_{i}\right)=0,
\end{aligned}
$$

or

$$
\begin{aligned}
\eta_{Q} & =1 \mu_{Q}\left(Z_{i}\right)=\nu_{Q}\left(Z_{i}\right) \\
& =\pi_{Q}\left(Z_{i}\right)=0,
\end{aligned}
$$

or

$$
\begin{aligned}
v_{Q}\left(Z_{i}\right) & =1 \\
\mu_{Q}\left(Z_{i}\right) & =\eta_{Q}\left(Z_{i}\right)=\pi_{Q}\left(Z_{i}\right)=0,
\end{aligned}
$$

or

$$
\begin{aligned}
\pi_{Q}\left(Z_{i}\right) & =1 \mu_{Q}\left(Z_{i}\right) \\
& =\eta_{Q}\left(Z_{i}\right) \\
& =v_{Q}\left(Z_{i}\right)=0 .
\end{aligned}
$$

Thus, $\theta(Q)=0 \Leftrightarrow Q$ is a crisp set. 
$P_{F S 2}$ (maximality). Equation (16) has the maximum value for

$$
\begin{aligned}
\theta(Q) & =\frac{1}{n} \sum_{i=1}^{n} \frac{1.582}{\exp }\left(\exp -\exp \left|\mu_{Q}\left(Z_{i}\right)+\eta_{Q}\left(Z_{i}\right)-\nu_{Q}\left(Z_{i}\right)-\pi_{Q}\left(Z_{i}\right)\right|\right): Q \\
Z_{i} & \in P_{F S}(Z)
\end{aligned}
$$

It is obvious that if $\mu_{Q}=\eta_{Q}=\nu_{Q}=\pi_{Q}=1 / 4$, this implies that entropy measure has the maximum value.

$P_{F S 3}$ (resolution). The property $P_{F S 2}$ shows that $\theta(Q)$ attains the maximum value if $\mu_{Q}=\eta_{Q}=\nu_{Q}=\pi_{Q}=1 / 4$. Therefore, if $\max \left\langle\mu_{Q}\left(Z_{i}\right), \eta_{Q}\left(Z_{i}\right), \nu_{Q}\left(Z_{i}\right)\right\rangle \leq 1 / 4$, and, $\mu_{\mathrm{Q}} \leq \mu_{R}, \eta_{\mathrm{Q}} \leq \eta_{R}$, and $\nu_{\mathrm{Q}} \leq \nu_{R}$. This concludes $\pi_{\mathrm{Q}}\left(Z_{i}\right) \geq$ $\pi_{R}\left(Z_{i}\right) \geq 1 / 4$.

Subsequently, if minimum $\left\langle\mu_{Q}\left(Z_{i}\right), \eta_{Q}\left(Z_{i}\right), v_{Q}\left(Z_{i}\right)\right\rangle$ $\geq 1 / 4$, Then, $\mu_{Q} \geq \mu_{R}, \eta_{Q} \geq \eta_{R}$, and $\nu_{Q} \geq v_{R}$. Thus, $\pi_{Q}\left(Z_{i}\right) \leq \pi_{R}\left(Z_{i}\right) \leq 1 / 4$. Therefore, use of equations (14) and (15). This is concluded that $\theta(Q)$ holds the property of resolution.
$P_{F S 4}$ (symmetry). This property is satisfied directly from the definition, i.e., $\theta(Q)=\theta\left(Q^{c}\right)$.

This is the complete proof of the theorem.

Theorem 2. . If any two $Q, R \in P_{F S}(Z): Q \subseteq R o r R \subseteq Q$, then

$$
\theta(Q \cup R)+\theta(Q \cap R)=\theta(Q)+\theta(R)
$$

Proof. Let $Z_{1}$ and $Z_{2}$ be the two parts of $\in Z$ (universal set) such that

$$
\begin{aligned}
& Z_{1}=\left\langle Z_{i} \in Z: Q \subseteq R\right\rangle \text {, } \\
& \left\langle Z_{2}=Z_{i} \in Z: R \subseteq Q\right\rangle \text {, } \\
& \mu_{\mathrm{Q}} \leq \mu_{R} \\
& \eta_{Q} \leq \eta_{R} \\
& v_{Q} \geq v_{R} \text { for all } Z_{i} \in Z_{1} \text {, } \\
& \mu_{\mathrm{Q}} \geq \mu_{R} \\
& \eta_{\mathrm{Q}} \geq \eta_{R} \text {, } \\
& v_{Q} \leq \nu_{R} \text { for all } Z_{i} \in Z_{2} \text {, } \\
& \theta(Q \cup R)=\frac{1.582}{n \exp } \sum_{i=1}^{n}\left(\exp -\exp \left|\mu_{(\mathrm{Q} \cup R)}\left(Z_{i}\right)+\eta_{(\mathrm{Q} \cup R)}\left(Z_{i}\right)-\nu_{(\mathrm{Q} \cup R)}\left(Z_{i}\right)-\pi_{(\mathrm{Q} \cup R)}\left(Z_{i}\right)\right|\right) \text {, } \\
& \theta(Q \cup R)=\frac{1.582}{n \exp } \sum_{Z_{1}}\left(\exp -\exp \left|\mu_{(\mathrm{Q} \cup R)}\left(Z_{i}\right)+\eta_{(\mathrm{Q} \cup R)}\left(Z_{i}\right)-\nu_{(\mathrm{Q} \cup R)}\left(Z_{i}\right)-\pi_{(\mathrm{Q} \cup R)}\left(Z_{i}\right)\right|\right) \\
& +\frac{1.582}{n \exp } \sum_{Z_{2}}\left(\exp -\exp \left|\mu_{(\mathrm{Q} \cup R)}\left(Z_{i}\right)+\eta_{(\mathrm{Q} \cup R)}\left(Z_{i}\right)-\nu_{(\mathrm{Q} \cup R)}\left(Z_{i}\right)-\pi_{(\mathrm{Q} \cup R)}\left(Z_{i}\right)\right|\right), \\
& \theta(Q \cup R)=\frac{1.582}{n \exp } \sum_{Z_{1}}\left(\exp -\exp \left|\mu_{R}\left(Z_{i}\right)+\eta_{R}\left(Z_{i}\right)-\nu_{R}\left(Z_{i}\right)-\pi_{R}\left(Z_{i}\right)\right|\right) \\
& +\frac{1.582}{n \exp } \sum_{Z_{2}}\left(\exp -\exp \left|\mu_{Q}\left(Z_{i}\right)+\eta_{Q}\left(Z_{i}\right)-v_{Q}\left(Z_{i}\right)-\pi_{Q}\left(Z_{i}\right)\right|\right) .
\end{aligned}
$$

As accordingly, 


$$
\begin{aligned}
\theta(\mathrm{Q} \cap R)= & \frac{1.582}{n \exp } \sum_{Z_{1}}\left(\exp -\exp \left|\mu_{(\mathrm{Q} \cap R)}\left(Z_{i}\right)+\eta_{(\mathrm{Q} \cap R)}\left(Z_{i}\right)-v_{(\mathrm{Q} \cap R)}\left(Z_{i}\right)-\pi_{((\mathrm{Q} \cap R))}\left(Z_{i}\right)\right|\right) \\
& +\frac{1.582}{n \exp } \sum_{Z_{2}}\left(\exp -\exp \left|\mu_{(\mathrm{Q} \cap R)}\left(Z_{i}\right)+\eta_{(\mathrm{Q} \cap R)}\left(Z_{i}\right)-v_{(\mathrm{Q} \cap R)}\left(Z_{i}\right)-\pi_{(\mathrm{Q} \cap R)}\left(Z_{i}\right)\right|\right), \\
\theta(\mathrm{Q} \cap R)= & \frac{1.582}{n \exp } \sum_{Z_{1}}\left(\exp -\exp \left|\mu_{\mathrm{Q}}\left(Z_{i}\right)+\eta_{\mathrm{Q}}\left(Z_{i}\right)-\nu_{\mathrm{Q}}\left(Z_{i}\right)-\pi_{\mathrm{Q}}\left(Z_{i}\right)\right|\right) \\
& +\frac{1.582}{n \exp } \sum_{Z_{2}}\left(\exp -\exp \left|\mu_{R}\left(Z_{i}\right)+\eta_{R}\left(Z_{i}\right)-v_{R}\left(Z_{i}\right)-\pi_{R}\left(Z_{i}\right)\right|\right) .
\end{aligned}
$$

Therefore, equations (23) and (24) prove that

$$
\theta(Q \cup R)+\theta(Q \cap R)=\theta(Q)+\theta(R) .
$$

\section{The Proposed Picture Fuzzy Entropy Measure with Application in $M_{\mathrm{CDM}}$ Process}

The $M_{\mathrm{CDM}}$ process involves the different techniques to solve the decision and planning problems, which involve multiple criteria. The objective is to support decision-maker in tackling such problems. To attain the unique optimal solution of such problems, the decision-makers fixed a set of alternatives and criteria. The fuzzy set and its various extended forms were included in $M_{\mathrm{CDM}}$ techniques because of the vagueness and ambiguity in the data analysis. Therefore, fuzzy sets have a great importance in the decision-making process. The $M_{\mathrm{CDM}}$ problems may be symbolized as a matrix say $\left(P_{\mathrm{FDM}}\right)_{\check{m} \times \check{n}}$ which represents the $\check{m}$ alternatives $\mathrm{ALT}_{1}, \mathrm{ALT}_{2}, \ldots \ldots \ldots \ldots \ldots \mathrm{ALT}_{m}^{\prime \prime}$ and $\check{n}$ criteria " $C R_{1}, C R_{2} \ldots \ldots \ldots \ldots C R_{n}^{\prime \prime}$ in the shape of rows and columns or vice versa. The entries in $\left(P_{F M}\right)_{\check{m} \times \check{n}}$ refer the degrees in accordance with $P_{F S}$ described in Definition 3. In practical problems where the human opinions are there, $P_{F S}$ is comparatively useful. Let the group of decision-makers $[\check{N}]$ expressed in $P_{F S}$ describe the (+) membership degree for support $\left[\check{n}_{\text {pos }}(i j)\right]$, neutral membership degree $\left[\check{n}_{\text {neu }}(i j)\right]$ signify the undecided or neutral, and (-) membership $\left[\check{n}_{\text {neg }}(i j)\right]$ represent unfavour of alternative for specific criteria. Consequently, the following statistical tools are used to express different degrees pertaining to $P_{F S}$.

$$
\begin{aligned}
& \check{\mu}_{i j}=\left\{\frac{\check{n}_{\text {pos }}(i j)}{\check{N}}\right\}, \\
& \check{\eta}_{i j}=\left\{\frac{\check{n}_{\text {neu }}(i j)}{\check{N}}\right\}, \\
& \check{v}_{i j}=\left\{\frac{\check{n}_{\text {neg }}(i j)}{\check{N}}\right\} .
\end{aligned}
$$

The statistical tool mentioned in (26)is significantly used if the available data are in the form of numerical quantity. In decision-making analysis, the different degrees of $P_{F S}$ are entirely reliant upon the single opinion or choice of decision-makers apart of any kind of information to render a decision. Such practical problems in $P_{F S}$ decision-making process are solved more effectively with greater accuracy.

5.1. Picture Fuzzy Sets with Proposed VIKOR Approach. The author [35] was the pioneer of VIKOR approach to obtain the most desired alternatives based upon the closeness index to the $(+)$ ideal solution and farthest from the (-) ideal solution in decision-making problems. The key salient feature of present approach helps to provide the compromise solution. Initially, the idea of compromise solution was developed by [36] in1973. The following procedural steps are widely used to solve the fuzzy decision-making problems.

Step 1. Formation of picture fuzzy decision matrix $\left(P_{\mathrm{FDM}}\right)_{\check{m} \times \check{n}}$.

$\left(P_{\mathrm{FDM}}\right)_{\check{m} \times \check{n}}$ is constructed in such a way that entries of the matrix elements are computed in accordance with different membership degrees of $P_{F S}$ briefed in equation (26).

Step 2. Normalization of $\left(P_{\mathrm{FDM}}\right)_{\check{m} \times \check{n}}$.

The fabricated matrix $\left(P_{\mathrm{FDM}}\right)_{\check{m} \times \check{n}}$ is normalized as shown in Table 1.

Where, $\left\{\check{\mu}_{i j}, \check{\eta}_{i j}, \check{v}_{i j}\right\}$

$$
=\left\{\mu_{i j}, \eta_{i j}, v_{i j} \text { for benefit criteria } v_{i j}, \eta_{i j}, \mu_{i j}\right. \text { for cost criteria. }
$$

Step 3. Assessment of criteria weights

The choice of selecting the weights of criteria or attributes has a substantial role in the way out of the solution of $M_{\mathrm{CDM}}$ problems. The appropriate and justified assessment of criteria weights might lead to the desired result of a suitable alternative. Considering the classified the criteria weights in two categories, i.e., subjective and objective weights [37], the objective weight apprehends the criteria information in a quantified manner; therefore, entropy practice is the best reliable approach to capture and handle such information. Sometimes, in $M_{C D M}$ process, the decision-makers have the criteria weights information in separate manner, i.e., entirely known or unknown and may be partially known according to problem scenario. 
TABLE 1: The fabricated matrix $\left(P_{\mathrm{FDM}}\right)_{\check{m} \times \check{n} \text {. }}$.

\begin{tabular}{|c|c|c|c|c|}
\hline & $C R_{1}$ & $C R_{2}$ & $\ldots$ & $C R_{n}$ \\
\hline $\mathrm{ALT}_{1}$ & $\left\{\check{\mu}_{11}, \check{\eta}_{11}, \check{v}_{11}\right\}$ & $\left\{\check{\mu}_{12}, \check{\eta}_{12}, \check{v}_{12}\right\}$ & $\ldots$ & $\left\{\check{\mu}_{1 n}, \check{\eta}_{1 n}, \check{v}_{1 n}\right\}$ \\
\hline $\begin{array}{l}\mathrm{ALT}_{2} \\
:\end{array}$ & $\begin{array}{c}\left\{\check{\mu}_{21}, \check{\eta}_{21}, \check{v}_{21}\right\} \\
\vdots\end{array}$ & $\begin{array}{c}\left\{\check{\mu}_{22}, \check{\eta}_{22}, \check{v}_{22}\right\} \\
\vdots\end{array}$ & $\begin{array}{l}\cdots \\
\ddots \vdots\end{array}$ & $\left\{\check{\mu}_{2 n}, \check{\eta}_{2 n}, \check{v}_{2 n}\right\}$ \\
\hline $\mathrm{ALT}_{m}$ & $\left\{\check{\mu}_{m 1}, \check{\eta}_{m 1}, \check{v}_{m 1}\right\}$ & $\left\{\check{\mu}_{m 2}, \check{\eta}_{m 2}, \check{v}_{m 2}\right\}$ & $\ldots$ & $\left\{\check{\mu}_{m n}, \check{\eta}_{m n}, \check{v}_{m n}\right\}$ \\
\hline
\end{tabular}

Note. $\left\{\check{\mu}_{i j}, \check{\eta}_{i j}, \check{v}_{i j}\right\}=\left\{\mu_{i j}, \eta_{i j}, v_{i j}\right.$ for benefit criteria $v_{i j}, \eta_{i j}, \mu_{i j}$ for cost criteria.

As a result, the following approaches are used to compute the criteria weights for both the cases:

(a) Methodology for Unknown Criteria Weights. To compute the unspecified criteria-weight, the author [37] proposed the method.

$\hat{w}_{j}=\frac{I-\theta(Q)_{J}}{n-\sum_{j=1}^{n} \theta(Q)_{J}}: \quad j=1,2,3 \ldots \ldots n$,

where

$$
\theta(Q)=\frac{1}{n} \sum_{i=1}^{m} \frac{1.582}{\exp }\left(\exp -\exp \left|\mu_{i j}+\eta_{i j}-v_{i j}-\pi_{i j}\right|\right) \text {. }
$$

(b) Methodology for Partially Known Criteria Weights. There are many complexities which are cited by the decision-makers to solve the problems in the decision-making system such as paucity of time, information, and lack of expertise around problem domain. Therefore, the decision-makers are enabled to give their judgment or decision precisely in the form of numeral value. They often express their opinions of the judgment in intervals to overcome such incongruities. In this framework, to explore the attribute weights from the set of partial information, the decision-makers generally use the method of minimum entropy proposed by [38] Hence, the alternatives entropy across the distinct criteria $C R_{j}$ is presented as follows:

$$
\begin{gathered}
\hat{\alpha}\left(\operatorname{ALT}_{i}\right)=\sum_{j=1}^{n} \hat{\alpha}\left(\mu_{i j}, \eta_{i j}, v_{i j}, \pi_{i j}\right), \\
\text { such that } \hat{\alpha}\left(\mu_{i j}, \eta_{i j}, v_{i j}, \pi_{i j}\right)=\frac{1}{n} \sum_{i=1}^{m} \frac{1.582}{\exp }\left(\exp -\exp \left|\mu_{i j}+\eta_{i j}-v_{i j}-\pi_{i j}\right|\right) .
\end{gathered}
$$

Thus, the following programming model is frequently used by the decision-makers for the optimum criteria evaluation:

$$
\begin{aligned}
& (\hat{E})=\sum_{I=1}^{M} W_{j} \cdot \hat{\alpha}\left(\operatorname{ALT}_{i}\right)=\frac{1.582}{n \exp } \sum_{i=1}^{m} \sum_{j=1}^{n} w_{j}\left(\exp -\exp \left|\mu_{i j}+\eta_{i j}-v_{i j}-\pi_{i j}\right|\right), \\
& \text { where }\left\{w \in \beta \sum_{j=1}^{n} w_{j}=1 w_{j} \geq 1: \quad j=1,2 \ldots n .\right.
\end{aligned}
$$

$\beta$ denotes the set of partial known informations to evaluate the weights of different criteria.

Step 4. Determination of the relative ideal solution for $P_{F S}$.

In $M_{\mathrm{CDM}}$ problems, the ideal solution provides the best alternatives which maximize the most benefited attribute or criteria and minimize the least cost criteria. The objective of the VIKOR method is to opt the best alternative nearest to the $(+)$ ideal solution along with farthest away from the $(-)$ ideal solution. Firstly, the picture fuzzy relative $(+)$ ideal solution and (-) ideal solution are constructed to determine the alternatives.

For benefit criteria,

$$
\begin{aligned}
& \mathrm{ALT}^{+}=\left(\mathrm{ALT}_{1}^{+}, \mathrm{ALT}_{2}^{+}, \ldots \ldots \ldots \mathrm{ALT}_{n}^{+}\right), \\
& \mathrm{ALT}^{-}=\left(\mathrm{ALT}_{1}^{-}, \mathrm{ALT}_{2}^{-}, \ldots \ldots \ldots \mathrm{ALT}_{n}^{-}\right),
\end{aligned}
$$

where 


$$
\begin{aligned}
\operatorname{ALT}_{J}^{+} & =\left(\mu_{i j}^{+}, \eta_{i j}^{+}, v_{i j}^{+}\right)=\left(\left(\check{\mu}_{i j}\right),\left(\check{\eta}_{i j}\right),\left(\check{v}_{i j}\right)\right), \\
\pi_{i j}^{+} & =1-\mu_{i j}^{+}-\eta_{i j}^{+}-v_{i j}^{+} ; \quad j=1,2 \ldots n, \\
\operatorname{ALT}_{J}^{-} & =\left(\mu_{i j}^{-}, \eta_{i j}^{-}, \nu_{i j}^{-}\right)=\left(\left(\check{\mu}_{i j}\right),\left(\check{\eta}_{i j}\right),\left(\check{v}_{i j}\right)\right), \\
\pi_{i j}^{+} & =1-\check{\mu}_{i j}-\check{\eta}_{i j}-\check{v}_{i j} ; \quad j=1,2 \ldots n .
\end{aligned}
$$

For cost criteria,

$$
\begin{aligned}
\mathrm{ALT}^{+} & =\left(\mathrm{ALT}_{1}^{+}, \mathrm{ALT}_{2}^{+}, \ldots \ldots \ldots \mathrm{ALT}_{n}^{+}\right), \\
\mathrm{ALT}^{-} & =\left(\mathrm{ALT}_{1}^{-}, \mathrm{ALT}_{2}^{-}, \ldots \ldots \ldots \mathrm{ALT}_{n}^{-}\right) .
\end{aligned}
$$

where

$$
\begin{aligned}
\operatorname{ALT}_{J}^{+} & =\left(\mu_{i j}^{+}, \eta_{i j}^{+}, v_{i j}^{+}\right)=\left(\left(\check{\mu}_{i j}\right),\left(\check{\eta}_{i j}\right),\left(\check{v}_{i j}\right)\right), \\
\pi_{i j}^{+} & =1-\mu_{i j}^{+}-\eta_{i j}^{+}-v_{i j}^{+} ; \quad j=1,2, \ldots n, \\
\operatorname{ALT}_{J}^{-} & =\left(\mu_{i j}^{-}, \eta_{i j}^{-}, \nu_{i j}^{-}\right)=\left(\left(\check{\mu}_{i j}\right),\left(\check{\eta}_{i j}\right),\left(\check{v}_{i j}\right)\right), \\
\pi_{i j}^{+} & =1-\check{\mu}_{i j}-\check{\eta}_{i j}-\check{v}_{i j} ; \quad j=1,2 \ldots n .
\end{aligned}
$$

Step 5. Evaluation of compromise solution

In decision sciences, the VIKOR method is very useful for the compromise solution, when the preference of decision-makers about alternatives is conflicting from the set of criteria information. In the VIKOR method, the compromise solution is obtained with the use of $\left(L_{p \alpha}\right)$ metric which was earlier introduced by [36]. The metric $\left(L_{p}\right)$ is an aggregate function used as follows:

$$
\begin{gathered}
\hat{L}_{p, i}=\left[\sum_{j=1}^{n}\left(w_{j} \frac{\left(\mathrm{ALT}^{+}-\hat{\Phi}_{i j}\right)}{\left(\mathrm{ALT}^{+}-\mathrm{ALT}^{-}\right)}\right)^{p}\right]^{1 / p}, \\
p \in[1, \infty), i \in[1,2, \ldots \ldots m],
\end{gathered}
$$

where $A L T^{+}$and $A L T^{-}$are described in equations (33) and (35).

$$
\begin{aligned}
& \hat{\Phi}_{i j}=\left(\check{\mu}_{i j}, \check{\eta}_{i j}, \check{v}_{i j}\right), \\
& w_{j} \text { are the weight of the criteria } j^{t h} ; j=1 \ldots \ldots n
\end{aligned}
$$

The parameter $p$ has the distinct values varying between $[1, \infty)$ which imply the different meaning in perspective of group utility and individual regret. As the increased value of $p$, the individual regret is substantially increased and the group utility or efficacy is decreased Hence, the VIKOR method gives the compromise solution with maximum group efficacy $\left(L_{1, i}\right)$ and reduces the individual regret $\left(L_{\infty, i}\right)$ as follows:

$$
\begin{aligned}
\hat{G}_{u i} & =\hat{L}_{1, i} \\
& =\sum_{j=1}^{n}\left\{w_{j} \frac{\left(\mathrm{ALT}^{+}-\hat{\Phi}_{i j}\right)}{\left(\mathrm{ALT}^{+}-\mathrm{ALT}^{-}\right)}\right\},
\end{aligned}
$$

$$
\begin{aligned}
\hat{I}_{R i} & =\hat{L}_{\infty, i} \\
& =\sum_{j=1}^{n}\left\{w_{j} \frac{\left(\mathrm{ALT}^{+}-\hat{\Phi}_{i j}\right)}{\left(\mathrm{ALT}^{+}-\mathrm{ALT}^{-}\right)}\right\} .
\end{aligned}
$$

Step 6. VIKOR index coefficient.

The index coefficient $\left(I_{c}\right)$ in the VIKOR method is computed as

$$
\hat{I}_{c}=\widetilde{\Theta}\left\{\frac{\hat{G}_{u i}-\hat{G}_{u *}}{\stackrel{\wedge}{*}_{u}-\hat{G}_{u *}}\right\}+(1-\widetilde{\Theta})\left\{\begin{array}{l}
\hat{I}_{R i}-\hat{I}_{R *} \\
\stackrel{\wedge}{*}_{I_{R}}-\hat{I}_{R *}
\end{array}\right\},
$$

$$
\text { where }\left\{\begin{array}{l}
\hat{G}_{u}^{*}=\hat{G}_{u i}, \\
\hat{G}_{u *}=\hat{G}_{u i}, \\
\wedge^{*}=\hat{I}_{R i}, \\
\hat{I}_{R *}=\hat{I}_{R i} .
\end{array}\right.
$$

In addition, the parameters $(\widetilde{\Theta})$ and $(1-\widetilde{\Theta})$ represent the group utility weight and individual regret as per the choice of its value by decision-makers as follows:

$I F \widetilde{\Theta}=\{0.5 \Rightarrow$ consenus $>0.5 \Rightarrow$ voting by majority $<0.5 \Rightarrow$ Veto.

Step 7. Finally, the ascending order of the determined values of $G_{u i}, I_{R i}$, and $I_{c}$ is arranged, and for the most preferred alternatives, the CONI and CONII are two respective conditions satisfied as

$\mathrm{CON} I \Rightarrow$ Aceptable Advantage $:$ IF the value,

$\left[\hat{I}\left(\mathrm{ALT}^{2}\right)-\hat{I}\left(\mathrm{ALT}^{1}\right)\right] \geq \frac{1}{n-1} ; \mathrm{ALT}^{1}$ and $\mathrm{ALT}^{2}$ are cataloged at $1^{\text {st }}$ and $2^{n d}$ place in distinct value of $\hat{I}_{c}$

$\mathrm{CON} I I \Rightarrow$ Aceptable Stablity : $\mathrm{ALT}_{1}$ must be cata loged at $1^{\text {st }}$ place in the distinct value of either $\hat{G}_{u i}$ and $\hat{I}_{R i}$. 
If the stated condition does not satisfy together, then we look upon a compromise solution proceed as follows.

Case 1. $\mathrm{ALT}^{1}$ and $\mathrm{ALT}^{2}$ are the compromise solutions if Acceptable Stability condition does not satisfy.
Case 2. If Acceptable Advantage is not accepted, then alternatives $\mathrm{ALT}^{1}, \mathrm{ALT}^{2}, \ldots \ldots \ldots \ldots \mathrm{ALT}^{m}$ have the compromise solution along with $\mathrm{ALT}^{m}$ if it does hold the following condition:

$$
\left[\hat{I}\left(A L T^{m}\right)-\hat{I}\left(\mathrm{ALT}^{1}\right)\right]<\frac{1}{n-1} ; m \Rightarrow \text { for some maximum and } n \text { implies the number of alternatives. }
$$

5.1.1. Picture Fuzzy Sets with Proposed TOPSIS Approach. The concept of TOSIS approach initiates and incorporates in $M_{\mathrm{CDM}}$ decision sciences by [39]. Since then, this method is prominently used to many complex practical problems in a fuzzy situation. The selection process of the best attributes in the proposed approach is to focus on the alternatives that one closest to the ideal solution and farthest, respectively, from the (-) ideal solution.

Further, to complete the calculative part of the $M_{\mathrm{CDM}}$ problem, we carry forward the first four steps stated above in the first approach.

Step 8. This step involves the picture fuzzy discriminant measure $E_{D}^{+}$and $E_{D}^{-}$for distinct attributes from $\mathrm{ALT}^{+}$and $\mathrm{ALT}^{-}$, respectively, with use of equation (7).

$$
\begin{aligned}
& E_{D}^{+}=\left[\sum_{j=1}^{n} w_{j}\left\{\hat{\Phi}_{i j}-\mathrm{ALT}^{+}\right\}^{2}\right]^{0.5}, \\
& E_{D}^{-}=\left[\sum_{j=1}^{n} w_{j}\left\{\hat{\Phi}_{i j}-\mathrm{ALT}^{-}\right\}^{2}\right]^{0.5} .
\end{aligned}
$$

Step 9. The relative closeness coefficient $\left(R_{c c}\right)$ is computed as follows:

$$
R_{c c}=\left\{\frac{E_{D}^{-}}{E_{D}^{-}+E_{D}^{+}}\right\} .
$$

Step 10. At the end, alternatives ranking have been done according to the ordering the distinct values of $R_{c c}$. The larger the value is, the most suitable the alternatives are. Thus, we have successfully presented the procedural steps to solve the picture fuzzy $M_{\mathrm{CDM}}$ problems by employing the proposed picture fuzzy entropy measure with the modified form of VIKOR and TOPSIS and for the sake of understanding the flow chart shown in Figure 3.

\section{Validation of Proposed Entropy Measure with Example}

The application of the PFS is to solve the MCDM problems, where simultaneously several attributes are likely to exist. In such type of environment, the human mindsets are always in dilemma; therefore, $P_{\mathrm{FSS}}$ is considerably used. In that point of view, a national welfare society conducted the social survey to get the public opinion for the functioning and implementation of the government policies for the national importance. They fix the framework of six different criteria, i.e.,

$$
\begin{aligned}
& C R_{1} \text { : unemployment } \\
& C R_{2} \text { : foreign relations } \\
& C R_{3} \text { : national education policy } \\
& C R_{4} \text { : financial services } \\
& C R_{5}: \text { strategy for COVID - } 19 \\
& C R_{6} \text { : national policies for social development and } \\
& \text { empowerment }
\end{aligned}
$$

And the national parties are classified into five categories, i.e., " $\mathrm{ALT}_{1}, \mathrm{ALT}_{2}, \mathrm{ALT}_{3}, \mathrm{ALT}_{4}, \mathrm{ALT}_{5}$. . The survey was conducted on a sample of $1000=N$ peoples. The results show 450 peoples in support with $C R_{1}, 320$ peoples unsupport with $C R_{1}, 120$ peoples are neutral, and 110 peoples are not participated, i.e., abstain. Then, with the use of equation (26), the entries of the $P_{F S}$ matrix can be determined as follows:

$$
\begin{aligned}
& \check{\mu}_{11}=\frac{450}{1000}, \\
& \check{\eta}_{11}=\frac{120}{1000}, \\
& \check{v}_{11}=\frac{320}{1000} .
\end{aligned}
$$

Further, entries of $\left(P_{\mathrm{FDM}}\right)_{5 \times 6}$ are computed in the same manner.

VIKOR approach for proposed entropy measure is as follows:

(1) The accumulated information as per opinion of peoples constitutes the normalized $\left(P_{\mathrm{FDM}}\right)_{5 \times 6}$ listed in Table 2.

(2) The notion $P_{\text {FDMw }}$ used for the calculated values of different criteria with information measure mentioned in (14) is listed in Table 3.

(3) Utilizing equation (28), the weights are determined for the defined criteria throughout the alternatives with use of values $P_{F D M W}$ catalogued in Table 4 .

(4) The values for $\mathrm{ALT}^{+}$and $\mathrm{ALT}^{-}$are computed with use of equation (34) as listed in Table 5. 


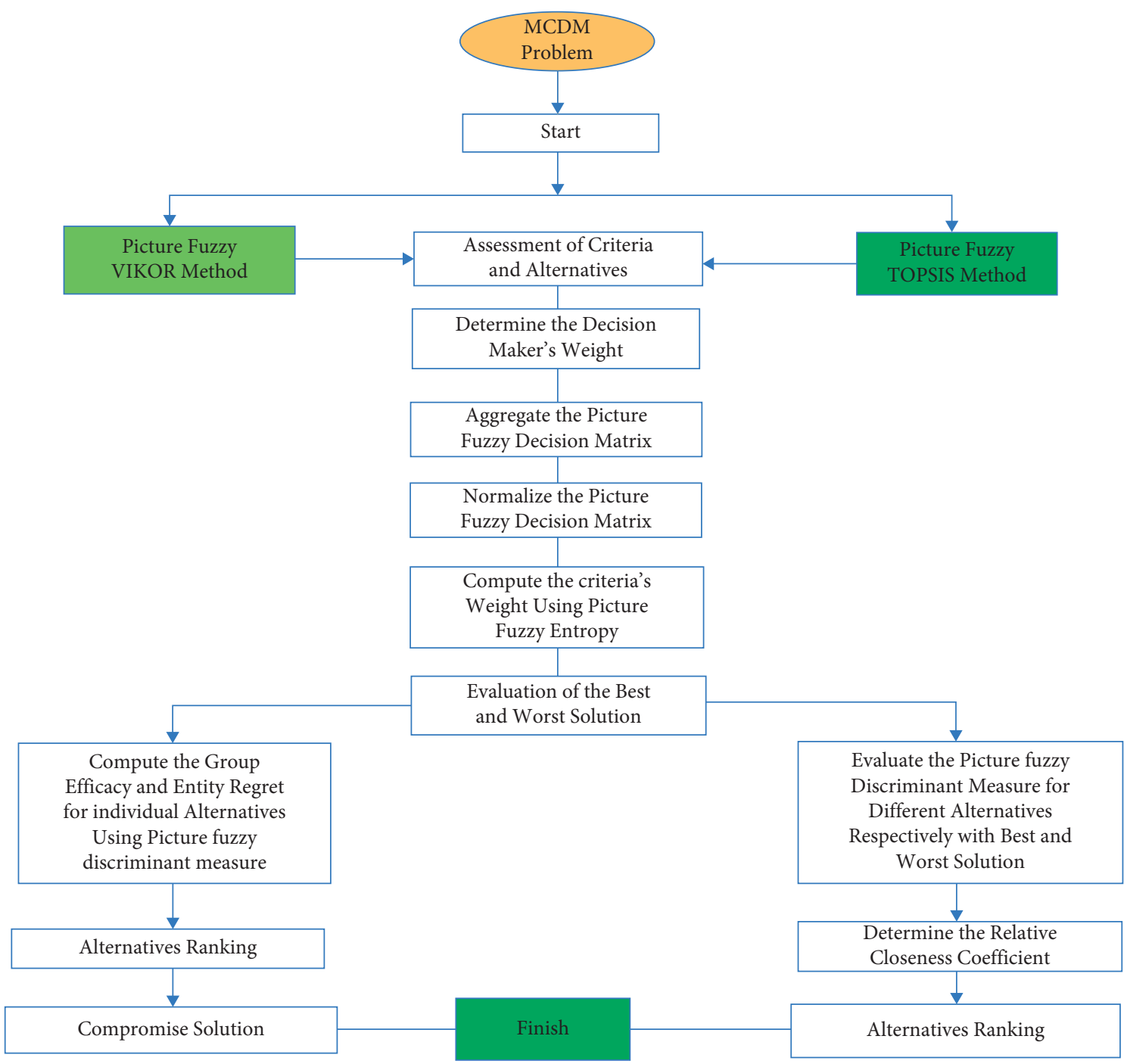

FiguRE 3: The procedural steps to solve the picture fuzzy $\mathrm{M}_{\mathrm{CDM}}$ problems by employing the proposed picture fuzzy entropy measure with the modified form of VIKOR and TOPSIS.

TABLE 2: Opinion of peoples constitutes the normalized $\left(P_{\mathrm{FDM}}\right)_{5 \times 6}$.

\begin{tabular}{lcccccr}
\hline$C R_{1}$ & $C R_{2}$ & $C R_{3}$ & $C R_{4}$ & $C R_{5}$ & $C R_{6}$ \\
\hline $\mathrm{ALT}_{1}$ & $0.45,0.32,0.12$ & $0.34,0.15,0.07$ & $0.69,0.06,0.17$ & $0.78,0.02,0.12$ & $0.84,0.04,0.08$ & $0.13,0.53,0.05$ \\
$\mathrm{ALT}_{2}$ 0.46, 0.05, 0.12 & $0.18,0.13,0.31$ & $0.81,0.11,0.04$ & $0.69,0.12,0.11$ & $0.36,0.32,0.31$ & $0.05,0.66,0.16$ \\
$\mathrm{ALT}_{3}$ 0.24, 0.27, 0.12 & $0.57,0.10,0.27$ & $0.81,03,0.10$ & $0.48,0.24,0.23$ & $0.17,0.58,0.16$ & $0.77,0.04,0.12$ \\
$\mathrm{ALT}_{4}$ & $0.36,0.24,0.08$ & $0.4,0.23,0.34$ & $0.08,0.72,0.06$ & $0.23,0.14,0.15$ & $0.28,0.28,0.28$ & $0.59,0.10,0.20$ \\
$\mathrm{ALT}_{5}$ & $0.40,0.30,0.14$ & $0.56,0.33,0.07$ & $0.64,0.12,0.21$ & $0.56,0.13,0.11$ & $0.51,0.10,0.36$ & $0.35,0.39,0.12$ \\
\hline
\end{tabular}

TABLE 3: Calculated values of different criteria with information measure.

\begin{tabular}{lcccccc}
\hline & $C R_{1}$ & $C R_{2}$ & $C R_{3}$ & $C R_{4}$ & $C R_{5}$ & $C R_{6}$ \\
\hline$P_{\text {FDMV }}$ & 0.82895 & 0.72463 & 0.48285 & 0.65164 & 0.69809 & 0.66986 \\
\hline
\end{tabular}

TABLE 4: The weights for the defined criteria throughout the alternatives with use of values $P_{\text {FDMW }}$.

\begin{tabular}{cccccc}
\hline$\widehat{W}_{1}$ & $\widehat{W}_{2}$ & $\widehat{W}_{3}$ & $\widehat{W}_{4}$ & $\widehat{W}_{5}$ & $\widehat{W}_{6}$ \\
\hline 0.08798 & 0.14165 & 0.26602 & 0.17920 & 0.15530 & 0.16982 \\
\hline
\end{tabular}


TABLE 5: The values for $\mathrm{ALT}^{+}$and $\mathrm{ALT}^{-}$.

\begin{tabular}{lllllll}
\hline ALT $^{+}$ & $0.46,0.05,0.08$ & $0.57,0.10,0.07$ & $0.81,0.03,0.04$ & $0.78,0.02,0.11$ & $0.84,0.04,0.08$ & $0.77,0.04,0.05$ \\
ALT $^{-}$ & $0.24,0.32,0.14$ & $0.18,0.33,0.34$ & $0.08,0.72,0.21$ & $0.23,0.24,0.23$ & $0.17,0.58,0.36$ & $0.05,0.66,0.20$ \\
\hline
\end{tabular}

TABLE 6: The computed values for $\widehat{G}_{u i}, \widehat{I}_{R i}$, and $\widehat{I}_{c}$.

\begin{tabular}{lccccc}
\hline & $\mathrm{ALT}_{1}$ & $\mathrm{ALT}_{2}$ & $\mathrm{ALT}_{3}$ & $\mathrm{ALT}_{4}$ & $\mathrm{ALT}_{5}$ \\
\hline$\widehat{\mathrm{G}}_{u i}$ & 0.3038 & 0.4965 & 0.3154 & 0.6652 & 0.4024 \\
$\widehat{I}_{R i}$ & 0.134 & 0.1831 & 0.099 & 0.2425 & 0.1103 \\
$\widehat{I}_{c}$ & 0.1219 & 0.5596 & 0.016 & 1 & 0.1757 \\
\hline
\end{tabular}

TABLE 7: The computed values for $\widehat{G}_{u i}, \widehat{I}_{R i}$, and $\widehat{I}_{c}$.

\begin{tabular}{lccccc}
\hline & $\mathrm{ALT}_{1}$ & $\mathrm{ALT}_{2}$ & $\mathrm{ALT}_{3}$ & $\mathrm{ALT}_{4}$ & $\mathrm{ALT}_{5}$ \\
\hline$\widehat{G}_{u i}$ & I & IV & II & V & III \\
$\widehat{I}_{R i}$ & III & IV & I & V & II \\
$\widehat{I}_{c}$ & II & IV & I & V & III \\
\hline
\end{tabular}

(5) Table 6 briefs the computed values for $\hat{G}_{u i}, \hat{I}_{R i}$, and $\hat{I}_{c}$ by using equations (39), (40), and (41).

(6) In accordance with the computed values for $G_{u i}, I_{R i}$, and $I_{c}$, the ranking of the alternatives is shown in Table 7.

(7) The indexing shows $A L T_{1}$ and $A L T_{3}$ located at $2^{\text {nd }}$ and $1^{\text {st }}$ position in Table 7 .

The CONI condition $\left[\hat{I}(\mathrm{ALT})^{1}-\hat{I}(\mathrm{ALT})^{3}\right]=$ $0.1219-0.016=0.1059 \geq \neq / 6-1=0.2$ does not hold.

Therefore, we proceed for the compromise solution, i.e.,

$$
\begin{aligned}
{\left[\hat{I}\left(\mathrm{ALT}^{1}\right)-\hat{I}\left(\mathrm{ALT}^{3}\right)\right] } & =0.1219-0.016 \\
& =0.1059<\frac{1}{6-1}=0.2 \\
{\left[\hat{I}\left(\mathrm{ALT}^{2}\right)-\hat{I}\left(\mathrm{ALT}^{3}\right)\right] } & =0.5596-0.016 \\
& =0.5436>\frac{1}{6-1}=0.2, \\
{\left[\hat{I}\left(\mathrm{ALT}^{4}\right)-\hat{I}\left(\mathrm{ALT}^{3}\right)\right] } & =1-0.016 \\
& =0.984>\frac{1}{6-1}=0.2, \\
{\left[\hat{I}\left(\mathrm{ALT}^{5}\right)-\hat{I}\left(\mathrm{ALT}^{3}\right)\right] } & =0.1757-0.016 \\
& =0.1597<\frac{1}{6-1}=0.2 .
\end{aligned}
$$

Thus, $\mathrm{ALT}^{1}, \mathrm{ALT}^{3}$, and $\mathrm{ALT}^{5}$ hold the CONII condition, and the alternatives $\mathrm{ALT}^{1}, \mathrm{ALT}^{3}$, and $\mathrm{ALT}^{5}$ are the compromise solution.
TABLE 8: The picture fuzzy discriminant measures $E_{D}^{+}$and $E_{D}^{-}$are computed for distinct attributes from $\mathrm{ALT}^{+}$and $\mathrm{ALT}^{-}$.

\begin{tabular}{cccccc}
\hline & $\mathrm{ALT}_{1}$ & $\mathrm{ALT}_{2}$ & $\mathrm{ALT}_{3}$ & $\mathrm{ALT}_{4}$ & $\mathrm{ALT}_{5}$ \\
\hline$E_{D}^{+}$ & 0.42005 & 0.48385 & 0.40190 & 0.63509 & 0.33341 \\
$E_{D}^{-}$ & 0.59931 & 0.57940 & 0.72670 & 0.41747 & 0.61122 \\
\hline
\end{tabular}

TABLE 9: The value of relative closeness coefficient $\left(R_{c c}\right)$.

\begin{tabular}{lcccc}
\hline $\mathrm{ALT}_{1}$ & $\mathrm{ALT}_{2}$ & $\mathrm{ALT}_{3}$ & $\mathrm{ALT}_{4}$ & $\mathrm{ALT}_{5}$ \\
\hline 0.5879 & 0.5449 & 0.6438 & 0.3966 & 0.6470 \\
\hline
\end{tabular}

TABLE 10: The indexing of the alternatives in descending order.

\begin{tabular}{lcccc}
\hline $\mathrm{ALT}_{1}$ & $\mathrm{ALT}_{2}$ & $\mathrm{ALT}_{3}$ & $\mathrm{ALT}_{4}$ & $\mathrm{ALT}_{5}$ \\
\hline $\mathrm{III}$ & IV & II & V & I \\
\hline
\end{tabular}

TOPSIS approach

Proceed with the same manner up to Step 4.

(8) The picture fuzzy discriminant measures $E_{D}^{+}$and $E_{D}^{-}$ are computed for distinct attributes from $\mathrm{ALT}^{+}$and $\mathrm{ALT}^{-}$, respectively, with use of equation (46) and listed in Table 8.

(9) The value of relative closeness coefficient $\left(R_{c c}\right)$ degree with use of (47) is mentioned in Table 9.

Finally, the indexing of the alternatives in descending order list is shown in Table 10.

From the indexing of the alternatives, it is concluded that $\mathrm{ALT}_{5}$ is the most desirable alternative.

\section{Comparative Evaluation}

To verify the effectiveness and practicability of the proposed information measure with TOSIS and VIKOR approaches, the result prevails in such a way that the TOPSIS method provides the best alternatives $A L T_{5}$ whereas VIKOR has a compromise solution, i.e., $\mathrm{ALT}^{1}, \mathrm{ALT}^{3}$, and $\mathrm{ALT}^{5}$. Thus, it is quite natural to think about the most benefited alternative. The authors [40] have briefly explained the relative difference between these two approaches for selection of best alternative. The feasible compromise solution in the VIKOR approach formexd a consent of mutual compromises focussed on optimising $G_{u i}$ and minimising $I_{R i}$; however, the TOPSIS approach adopts the feasible solution without considering the relative importance of the distances which are nearest and farthest from an ideal solution. In the perspective of the proposed example, if the results are interpreted in the broader sense, then it shows that national party $\mathrm{ALT}_{5}$ is the choice of the peoples in majority and would be able to form the government. In compromise solution, it reveals that the parties $\mathrm{ALT}^{1}, \mathrm{ALT}^{3}$, and $\mathrm{ALT}^{5}$ are also the choice of the peoples which leads the alliance situation to establish the 
government. There is also the possibility of an alliance between the parties either two or three to have a majority criterion to form the government.

\section{Concluded Remarks}

Till now, several mindsets have developed different approaches or methods of information measure to explore the information in picture fuzzy environment, and still the researchers are working hard to develop such information measures which are more reliable, precise, and informative reasonably with existing measure techniques. The proposed picture novel entropy was validated with the two different approaches. The results reveal that the best alternative is analogous in both approaches and proved that information measure is quite appropriate to solve the complex issues on $M_{\mathrm{CDM}}$ system. The trustworthiness and practical applicability of the proposed work proved to improve the voting system and the opinion of the peoples about the parties to the national importance. The proposed model could be used to predict the future outcomes of the polling. The novel research work is significantly suitable to the $M_{\mathrm{CDM}}$ complex multivariable problems, relating to the neutral factors or variables. The role of neutral variables in complex issues affects the result of decision-makers. This advantage of the proposed work facilitates the decision-makers to handle the ambiguity that arises due to neutral variables in complex issues. Therefore, it concluded that novel picture information measure is more reliable, sophisticated, and informative as well as simpler, to tackle the uncertainty or vagueness more precisely and effectively in a picture fuzzy environment.

8.1. The Advantage and Future Scope of the Current Research. The present research work could be extensively applied as a model to predict the forthcoming results in the field of data analysis, i.e., healthcare, agriculture, smart cities, and many more approaches in relation to sustainable development. Further, it can be explored to $P_{\mathrm{FSS}}$ in terms of divergence measure, intervalued, and many more. The proposed research work could be bridged between the complex evidence theory as well as quantum mechanics theory to envisage the human decision behaviours in decision theory. Moreover, the presented research work model is also utilized in intelligent generalized quality-based approach which is capable enough to fuse the complex multivariable informations. In fact, decision-makers are comfortable to express the human judgments or suggestions in the linguistic form in picture fuzzy environment. Therefore, present research works can be utilized in fuzzy linguistic models.

$\begin{array}{ll}\text { Abbreviations } \\ F_{s s}: & \text { Fuzzy set } \\ F_{s s s}: & \text { Fuzzy set } \\ I_{F s}: & \text { Intuitionistic fuzzy set } \\ I_{F s s}: & \text { Intuitionistic fuzzy set } \\ P_{F s}: & \text { Picture fuzzy set } \\ P_{F s s}: & \text { Picture fuzzy set }\end{array}$

$M_{\mathrm{CDM}}: \quad$ Multicriteria decision-making

$P_{\mathrm{PFS}}$ : $\quad$ Pythagorean fuzzy sets

TOPSIS: Technique for order preference by similarity to ideal solution

VIKOR: VIse Kriterijumska Optimizacija I Kompromisno Resenje

$\mu$ : $\quad$ Degree of membership function

$v$ : Degree of nonmembership function

$\eta$ : $\quad$ Degree of netural-membership function

刃: $\quad$ Degree of hesitency or refusal

$G_{u i}: \quad$ Group efficacy or group utility

$I_{R i}$ : Entity regret or individual regret.

\section{Data Availability}

The data used to support the findings of the study are included within the article.

\section{Conflicts of Interest}

The authors declare that there are no conflicts of interest regarding the publication of this article.

\section{Acknowledgments}

The authors would like to thank Chancellor and Vice Chancellor of Shoolini University, India, for their support.

\section{References}

[1] M. Demetgul, O. Ulkir, and T. Waqar, "Washing machine using fuzzy logic," Automation, Control and Intelligent Systems, vol. 2, no. 3, p. 27, 2014.

[2] S. Boverie and B. Demaya, J. M. L. Quellec, A. Titli, Contribution of fuzzy logic control to the improvement of modern car performances," Control Engineering Practice, vol. 1, no. 2, pp. 291-297, 1993.

[3] S. Mohanaselvi and B. Shanpriya, "Application of fuzzy logic to control traffic signals," in AIP Conference ProceedingsAIP Publishing LLC, Melville, NY, USA, 2019.

[4] L. A. Zadeh, "Fuzzy sets," Information and Control, vol. 8, no. 3, pp. 338-353, 1965.

[5] K. T. Atanassov, "Intuitionistic fuzzy sets," Fuzzy Sets and Systems, vol. 20, no. 1, pp. 87-96, 1986.

[6] M. Gulzar, D. Alghazzawi, M. H. Mateen, and N. Kausar, "A certain class of t-intuitionistic fuzzy subgroups," IEEE Access, vol. 8, pp. 163260-163268, 2020.

[7] M. Gulzar, M. H. Mateen, D. Alghazzawi, and N. Kausar, “A novel applications of complex intuitionistic fuzzy sets in group theory," IEEE Access, vol. 8, pp. 196075-196085, 2020.

[8] H. Alolaiyan, H. Alshehri, M. H. Mateen, and D. Pamucar, "A novel algebraic structure of $(\alpha, \beta)$-complex fuzzy subgroups," Entropy, vol. 23, no. 8, p. 992, 2021.

[9] B. C. Cuong and V. Kreinovich, "Picture Fuzzy Sets-a new concept for computational intelligence problems," in Proceedings of the 3rd world congress on information and communication technologies (WICT 2013), IEEE, Hanoi, Vietnam, December 2013.

[10] P. Dutta, "Medical diagnosis via distance measures on picture fuzzy sets," Advances in Modelling and Analysis A, vol. 54, no. 2, pp. 657-672, 2017. 
[11] R. Sahu, S. R. Dash, and S. Das, "Career selection of students using hybridized distance measure based on picture fuzzy set and rough set theory," Decision Making Applications in Management and Engineering, vol. 4, no. 1, pp. 104-126, 2021.

[12] A. H. Ganie, S. Singh, and S. Lalotra, "Some new correlation coefficients of picture fuzzy sets with applications," International Journal of Fuzzy System Applications, vol. 32, no. 16, pp. 1-17, 2020.

[13] J. K. Muhammad, K. Poom, D. Wejdan, K. Wiyada, and S. Zahir, "Bi-parametric distance and similarity measures of picture fuzzy sets and their applications in medical diagnosis," vol. 22, no. 2, pp. 201-212, 2021.

[14] E. Egrioglu, E. Bas, U. Yolcu, and M. Y. Chene, "Picture fuzzy time series: defining, modeling and creating a new forecasting method," Engineering Applications of Artificial Intelligence, vol. 88, Article ID 103367, 2020.

[15] G. Wei, S. Zhang, J. Lu, J. Wu, and C. Wei, "An extended bidirectional projection method for picture fuzzy MAGDM and its application to safety assessment of construction project," IEEE Access, vol. 7, pp. 166138-166142, 2019.

[16] L. Wang and H. Garg, "Algorithm for multiple attribute decision-making with interactive archimedean norm operations under pythagorean fuzzy uncertainty," International Journal of Computational Intelligence Systems, vol. 14, no. 1, pp. 503-527, 2021.

[17] G. Wei, "Picture fuzzy cross-entropy for multiple attribute decision making problems," Journal of Business Economics and Management, vol. 17, no. 4, pp. 491-502, 2016.

[18] N. X. Thao, "Similarity measures of picture fuzzy sets based on entropy and their application in MCDM," Pattern Analysis \& Applications, vol. 23, no. 3, pp. 1203-1213, 2020.

[19] V. Arya and S. Kumar, "A novel TODIM-VIKOR approach based on entropy and Jensen-Tsalli divergence measure for picture fuzzy sets in a decision-making problem," International Journal of Intelligent Systems, vol. 35, no. 12, pp. 2140-2180, 2020.

[20] R. Joshi, "A novel decision-making method using R-Norm concept and VIKOR approach under picture fuzzy environment," Expert Systems with Applications, vol. 147, Article ID 113228, 2020.

[21] N. G. Suman, "Use of (R, S)-Norm concept and TOPSIS approach under picture fuzzy environment for application in multi criteria decision making issues," Materials Today: Proceedings, 2021, in Press.

[22] D. Liu, Y. Luo, and Z. Liu, “The linguistic picture fuzzy set and its application in multi-criteria decision-making: an illustration to the TOPSIS and TODIM methods based on entropy weight," Symmetry, vol. 12, no. 7, 2020.

[23] F. Xiao, "CEQD: a complex mass function to predict interference effects," IEEE Transactions on Cybernetics, 2021.

[24] F. Xiao, "GIQ: a generalized intelligent quality-based approach for fusing multi-source information," IEEE Transactions on Fuzzy Systems, vol. 29, 2020.

[25] B. C. Cuong and V. Kreinovich, "Picture fuzzy sets," Journal of Computer Science and Cybernetics, vol. 30, no. 4, pp. 409-420, 2014.

[26] A. D. Luca and S. Termini, "A definition of a nonprobabilistic entropy in the setting of fuzzy sets theory," Information and Control, vol. 20, no. 4, pp. 301-312, 1972.

[27] W. L. Hung and M. S. Yang, "Fuzzy entropy on intuitionistic fuzzy sets," International Journal of Intelligent Systems, vol. 21, no. 4, pp. 443-451, 2006.
[28] C. E. Shannon, "A mathematical theory of communication," The Bell System Technical Journal, vol. 27, no. 3, pp. 379-423, 1948.

[29] R. Verma and B. D. Sharma, "Exponential entropy on intuitionistic fuzzy sets," Journal of Kybernetika -Praha, vol. 49, no. 1, pp. 114-127, 2013.

[30] R. Kumar and N. G. Suman, "A novel pythagorean fuzzy entropy measure using MCDM application in preference of the advertising company with TOPSIS approach," Materials Today: Proceedings, 2021, in Press.

[31] X. Liu, J. Wu, S. Zhang, and Z. W. Wang, "Extended cumulative residual entropy for emergency group decisionmaking under probabilistic hesitant fuzzy environment," International Journal of Fuzzy Systems, vol. 87, pp. 1-21, 2021.

[32] H. Garg, "Intuitionistic fuzzy hamacher aggregation operators with entropy weight and their applications to multi-criteria decision-making problems," Iranian Journal of Science and Technology, Transactions of Electrical Engineering, vol. 43, no. 3, pp. 597-613, 2019.

[33] H. Garg, "Generalized intuitionistic fuzzy entropy-based approach for solving multi-attribute decision-making problems with unknown attribute weights," Proceedings of the National Academy of Sciences, India Section A: Physical Sciences, vol. 89, no. 1, pp. 129-139, 2019.

[34] E. Szmidt and J. Kacprzyk, "Distances between intuitionistic fuzzy sets," Fuzzy Sets and Systems, vol. 114, no. 3, pp. 505-518, 2000.

[35] S. Opricovic and G.-H. Tzeng, "Extended VIKOR method in comparison with outranking methods," European Journal of Operational Research, vol. 178, no. 2, pp. 514-529, 2007.

[36] P.-L. Yu, "A class of solutions for group decision problems," Management Science, vol. 19, no. 8, pp. 936-946, 1973.

[37] T.-Y. Chen and C.-H. Li, "Determining objective weights with intuitionistic fuzzy entropy measures: a comparative analysis," Information Sciences, vol. 180, no. 21, pp. 4207-4222, 2010.

[38] J.-Q. Wang and P. Wang, "Intuitionistic linguistic fuzzy multi-criteria decision-making method based on intuitionistic fuzzy entropy," Control and Decision, vol. 27, no. 11, pp. 1694-1698, 2012.

[39] C.-L. Hwang and K. Yoon, "Methods for multiple attribute decision making," in Multiple Attribute Decision MakingSpringer, New York, NY, USA, 1981.

[40] O. Serafim and H. T. Gwo, "Compromise solution by MCDM methods: a comparative analysis of VIKOR and TOPSIS," European Journal of Operational Research, vol. 156, no. 2, pp. 445-455, 2004. 